The authors thank N. F. Foster for fabricating the CdS transducers, D. L. Perry for evaporating the antireflective coatings, K. Nassau for kindly supplying the lithium niobate crystal, and E. I. Gordon for many valuable discussions.

${ }^{1}$ G. B. Benedek and T. Greytak, Proc, IEEE 53, 1623 (1965). C. F. Quate, et al., Proc. IEEE 53, 1604 (1965). M. G. Cohen and E. I. Gordon, Bell System Tech.J. 44, 693 (1965). M. Born and E. Wolf, Principles of Optics (MacMillan, New York, 1964), 2nd ed., Chap. XII.
${ }^{2}$ R. Krishnan, Progress in Crystal Physics (Madras, Central Art Press, 1958).

${ }^{3}$ T. M. Smith and A. Korpel, IEEE Journal of Quantum Electronics QE-1, 283 (1965).

${ }^{4}$ K. Nassau and H. J. Levinstein, Appl. Phys. Letters 7, 69 (1965).

${ }^{5}$ E. G. Spencer, et al., Appl. Phys. Letters 7, 67 (1965). E. G. Spencer and P. V. Lenzo, IEEE Ultrasonics Symposium, Boston, December 1965. E. G. Spencer, IEEE Journal of Quantum Electronics, to be published.

${ }^{6}$ J. F. Nye, Physical Properties of Crystals (Clarendon Press, Oxford, 1960), p. 250.

${ }^{7}$ F. E. Borgnis, Phys. Rev. 98, 1000 (1955).

${ }^{8}$ W. Primak and D. Post, J. Appl. Phys. 30, 779 (1959).

${ }^{9}$ E. I. Gordon, to be published.

${ }^{10}$ G. D. Boyd, et al., Appl. Phys. Letters 5, 234 (1964).

\title{
PLASMA DENSITY MEASUREMENTS AT 100 KILOBARS OF PRESSURE*
}

\author{
(plasma generation; plasma confinement by detonation; \\ particle density $10^{23} \mathrm{~cm}^{-3} ; 10,000^{\circ} \mathrm{K} ; \mathrm{E} / \mathrm{T}$ )
}

\author{
James W. Robinson \\ Department of Electrical Engineering \\ The University of Michigan \\ Ann Arbor, Michigan \\ (Received 21 February 1966)
}

Pressures of 100 kilobars have been established in an underwater electrical discharge by the detonation of a few grams of a chemical explosive near the discharge path. At 100 kilobars, the plasma formed by the discharge has the density of a solid without the regularity of a lattice, and strong particle interactions have a very significant effect upon the properties of the plasma. Quantitative thermodynamic data have been obtained.

The plasma is produced by discharging a capacitor through a fine wire in water as E. A. Martin did in his work. ${ }^{1}$ The principal constituent of the plasma in the expanding cylindrical discharge column is water with metal vapor from the wire being a minor contaminant.

Without explosive, the plasma is confined by the inertial restraint of the surrounding water and by the magnetic pinch effect. At a rate of current rise of $10^{11} \mathrm{~A} / \mathrm{sec}$, the growth rate of the discharge column is such that the inertial and magnetic pressures are nearly equal, with the total pressure being 7.7 kilobars. As the rate of current rise is increased, the pressure is increased and the magnetic effect gains in relative importance.

Although higher rates of current rise produce

\footnotetext{
*This work was supported by a grant from the National Aeronautics and Space Administration.
}

higher pressures, the introduction of an explosive charge is desirable for obtaining pressures in the range of 100 kilobars. With a $10 \mathrm{-g}$ charge, a pressure pulse has been produced which decays to one-half its initial pressure in about $4 \mu \mathrm{sec}$. Thereby a confinement time sufficiently long for plasma diagnostic studies is obtained without an unusually high rate of sustained current rise. Since the plasma pressure has little dependence upon the rate of current rise when an explosive charge is used, there is no restriction upon the design of the capacitor bank which produces the plasma.

Experiments have been performed with the assembly illustrated in Fig. 1. The explosive, PETN, is formed into a $1 / 2 \times 2 \mathrm{in}$. cylinder which is radially confined by a massive steel container. A shock wave propagates upward from the explosive into the electrode region where the plasma is formed. The plasma column is confined by the high pressure of the water in the region behind the shock front and ahead of the explosive gases.

For diagnostic purposes, Kerr-cell photographs with negligible distortion are taken through the shock front above the assembly. The shock-front pressure and the rate of pressure decay are computed from shock velocity data. ${ }^{2}$ The plasma temperature is determined from measurements of radiation intensity, and the plasma energy from 
electrical measurements of the capacitor discharge. The details of the measurements and calculations follow, with some modifications, the procedures which have been described by Martin. ${ }^{1}$

Experiments can be classified into two modes. In the first, the electrical discharge is initiated before the shock front reaches the initiating wire. When the plasma column is compressed by the shock front, the water-plasma interface produces shock reflections which quickly equalize, leaving a uniform plasma. In the second mode, the discharge is delayed until after the shock front has passed the initiating wire, and the plasma column is formed in the region of high pressure.

A series of tests was performed with the assembly of Fig. I where the shock front from the explosive arrived at the plasma location $0.3 \mu \mathrm{sec}$ after the discharge was initiated. A period of $0.2 \mu \mathrm{sec}$ followed when the plasma column was being traversed by the incident and reflected shock fronts. In the compression process, the temperature fell from an

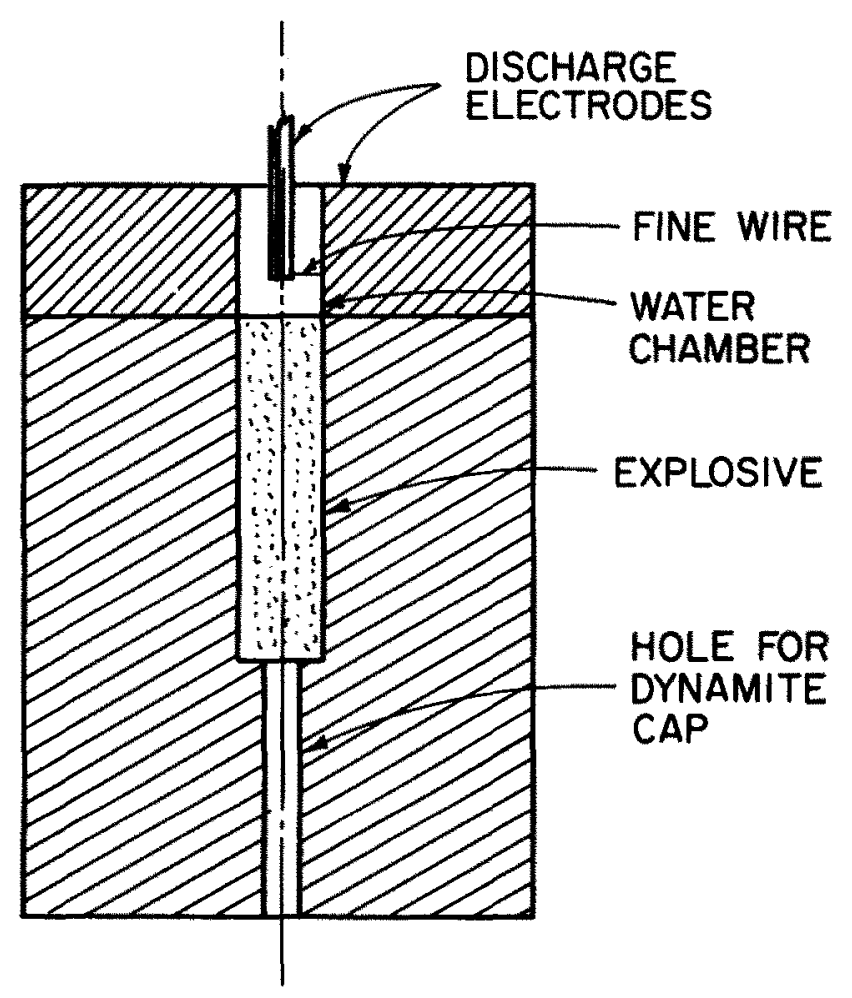

1 inch

Fig. 1. Apparatus for generating plasma at 100 kilobars of pressure. initial value of $32,000^{\circ} \mathrm{K}$ to $10,000^{\circ} \mathrm{K}$. The flattened column continued to expand without irregularities for approximately $0.4 \mu \mathrm{sec}$, after which the column split into two parallel paths. The rate of current rise was $8 \times 10^{10} \mathrm{~A} / \mathrm{sec}$.

During the uniform growth phase after compression, the pressure was 115 kilobars. The mechanical work done by the expanding column was subtracted from the electrical energy delivered to the plasma to obtain the net internal energy which was 50 $\mathrm{J} / \mathrm{mm}^{3}$. With the introduction of an excluded volume into a classical calculation of equilibrium properties, a theoretical prediction of internal energy was consistent with the experimental value. Atomic densities were estimated to be $10^{23} \mathrm{~cm}^{-3}$.

Comparable values of energy density were obtained when the arrival of the shock front preceded the initiation of the discharge. However, the plasma developed differently in this mode when an electrode system different from that shown in Fig. 1 was used. For these experiments, the electrodes were designed so that the shock wave was not directed vertically as in Fig. 1, but was allowed to diverge from the end of the explosive charge. Thus, somewhat lower pressures existed in the plasma. The discharge column developed into an array of two types of plasma distinguished by their temperatures. The column was not cylindrical but it bulged due to a more rapid growth of the hotter regions. The cooler regions had a smaller cross section and thus a higher current density.

Consequently, the cooler regions had the higher conductivity. Otherwise, the irregular formation would not have developed because these regions would have absorbed power at a faster rate and lost their identity. Actually the irregularities became more prominent as the column grew.

The variation in conductivity cannot be explained with a theory of metallic conduction because of the lack of an extended crystal structure, and a theory of gaseous conduction is certainly inappropriate. A model to be used for calculating conductivity could possibly be based upon a localized quasistatic ordering of ions with a one-electron approximation.

\footnotetext{
${ }^{1}$ Edward A. Martin, J. Appl. Phys. 31, 255-67 (1960).

John M. Walsh and Melvin H. Rice, J. Chem. Phys. 26, 828 (1957).
} 